\title{
High HIV Prevalence Among Men Who have Sex with Men in Soweto, South Africa: Results from the Soweto Men's Study
}

\author{
Tim Lane $\cdot$ H. Fisher Raymond $\cdot$ Sibongile Dladla \\ Joseph Rasethe $\cdot$ Helen Struthers · Willi McFarland • \\ James McIntyre
}

Published online: 7 August 2009

(C) The Author(s) 2009. This article is published with open access at Springerlink.com

\begin{abstract}
The Soweto Men's Study assessed HIV prevalence and associated risk factors among MSM in Soweto, South Africa. Using respondent driven sampling (RDS) recruitment methods, we recruited 378 MSM (including 15 seeds) over 30 weeks in 2008. All results were adjusted for RDS sampling design. Overall HIV prevalence was estimated at $13.2 \%$ (95\% confidence interval $12.4-13.9 \%$ ), with $33.9 \%$ among gay-identified men, $6.4 \%$ among bisexual-identified men, and $10.1 \%$ among straight-identified MSM. In multivariable analysis, HIV infection was associated with being older than 25 (adjusted odds ratio (AOR) 3.8, 95\% CI 3.2-4.6), gay self-identification (AOR 2.3, 95\% CI 1.8-3.0), monthly income less than ZAR500 (AOR 1.4, 95\% CI 1.2-1.7), purchasing alcohol or drugs in exchange for sex with another man (AOR 3.9, 95\% CI 3.2-4.7), reporting any URAI (AOR 4.4, 95\% CI 3.5-5.7), reporting between six and nine partners in the prior 6 months (AOR 5.7, 95\% CI 4.0-8.2), circumcision, (AOR $0.2,95 \%$ CI $0.1-0.2$ ), a regular female partner (AOR 0.2, 95\% CI 0.2-0.3), smoking marijuana in the last 6 months (AOR 0.6, 95\% CI 0.5-0.8), unprotected vaginal intercourse in the last 6 months (AOR 0.5, 95\% CI 0.4-0.6), and STI symptoms in the last year (AOR 0.7, 95\% CI
\end{abstract}

T. Lane $(\bowtie) \cdot$ W. McFarland

Center for AIDS Prevention Studies, University of California

San Francisco, San Francisco, CA, USA

e-mail: tim.lane@ucsf.edu

H. F. Raymond · W. McFarland

San Francisco Department of Public Health, San Francisco, CA, USA

S. Dladla $\cdot$ J. Rasethe $\cdot$ H. Struthers $\cdot$ J. McIntyre Perinatal HIV Research Unit, University of the Witwatersrand, Johannesburg, South Africa
0.5-0.8). The results of the Soweto Men's Study confirm that MSM are at high risk for HIV infection, with gay men at highest risk. HIV prevention and treatment for MSM are urgently needed.

Keywords Africa - Men who have sex with men . Gay men · HIV prevalence $\cdot$ Risk factors

\section{Introduction}

Although men who have sex with men (MSM) have been disproportionately affected by HIV since the beginning of the epidemic, research on the epidemiology of HIV among MSM populations MSM in sub-Saharan Africa is just beginning [1,2]. Published studies of MSM from Botswana, Malawi, Namibia, Senegal, South Africa, and Uganda have noted high rates of unprotected anal intercourse (UAI) between men [3-6]. In addition, the Senegal survey and VCT data from Kenya [7] report HIV prevalence figures for MSM much higher than their corresponding national prevalence estimates. A recent meta-analysis found African MSM are nearly four times more likely to be HIV infected than the general population [8]. Despite these findings, many African countries have yet to include MSM among their most at-risk populations in national HIV planning. Moreover, homosexuality is illegal in much of Africa. Lack of HIV data and criminalization of homosexuality may reinforce each other, keeping the full extent of the HIV epidemic among MSM from being addressed [9]. South Africa is an exception to this trend. Homosexuality was decriminalized in 1994, and more recently the country has included MSM in its 2007-2011 HIV and STI National Strategic Plan [10]. Nonetheless, even South Africa's 
response to the HIV prevention and treatment needs of MSM has suffered from a lack of behavioral and HIV prevalence data.

While some population-based surveys have found increased risk of HIV infection among men who report same-sex behavior [11], most behavioral and epidemiological studies with African MSM as the target population have relied on convenience or snowball samples of men who self-identify as homosexual within their cultural contexts [3, 5, 12-14]. While these studies have been an important to beginning investigations of the HIV epidemic among MSM where same sex behavior is stigmatized or illegal, more hidden, non-homosexually identified subpopulations of MSM may be underrepresented in these samples. The sexual behaviors and HIV prevalence of such men are important to understanding patterns of HIV transmission among MSM generally. Furthermore, selection bias limits the generalizability of results. The respondent driven sampling (RDS) methodology described by Heckathorn has the potential to reach more deeply into hidden MSM sub-populations and, by limiting recruitment and tracking the personal network size of participants, to minimize biases inherent in convenience and snowball sampling $[15,16]$. To date, only one published study of MSM in Africa has used RDS recruitment and estimation, but it was not able to measure HIV prevalence [4].

This paper presents results from The Soweto Men's Study, which assessed HIV prevalence and risk factors in a population of sexually active MSM in Soweto, South Africa, using RDS recruitment and analysis methods. Soweto is a peri-urban "township" roughly $15 \mathrm{~km}$ southwest of central Johannesburg with a population estimated between 1.5 and 3 million. The MSM population includes men who openly identify as "gay" or "bisexual", as well as many who identify as "straight" to keep their same-sex behaviors hidden from family, friends, or female partners. It is important to note that the "gay" identity claimed by Soweto MSM does not map neatly onto "western" or "global" gay identity as it is commonly understood. In preliminary ethnographic work, MSM associated gay identity with feminine gender identity - though it is important to note that "transgender" is not an identity category that any of our participants claimed.

The study took place at the University of the Witwatersrand's (Wits) Perinatal HIV Research Unit (PHRU) at Chris Hani-Baragwanath Hospital. PHRU and the University of California San Francisco's (UCSF) Center for AIDS Prevention Studies have collaborated on MSM HIV research since 2003. Unlike South Africa's other major urban centers (Cape Town, Durban, and Pretoria), no lesbian-gay-bisexual-transgender (LGBT) organization was working on HIV prevention activities with the Soweto MSM population at the time of our study.

\section{Methods}

The Soweto Men's Study sampled sexually active MSM who lived, worked, or socialized in Soweto. To begin RDS recruitment, we purposively selected 15 seeds that were diverse with respect to sexual identity, HIV status, and geographic distribution within Soweto. These seeds recruited additional MSM from their social networks using study coupons pre-printed with the Study's phone number and location. Staff screened recruits for eligibility in the study office. Participants were eligible if they were over age 18 ; lived, worked, or socialized in Soweto; had engaged in oral or anal intercourse with another man in the prior 6 months; had a valid study coupon and had not previously participated in the study; and were able to provide written informed consent. The study was approved by Wits's Human Research Ethics Committee and UCSF's Committee on Human Research.

The study questionnaire was based on a behavioral instrument used previously with this population [5]. Questions included standard demographic indicators; regular female and male sexual partnerships (someone the participant "lived with, saw a lot, and felt a special emotional commitment to for 3 months or more"); circumcision status; history of incarceration; age and condom use at sexual debut with men and women; history of coerced sex; transactional sex with men and women (sex in exchange for "expensive gifts," "money, food, or a place to sleep," and "drugs or alcohol"); and drug and alcohol use. The Alcohol Use Disorders Identification Test (AUDIT) was used to characterize drinking behavior [17]. AUDIT assessments include frequency of drinking, amount of alcohol consumed when drinking, and perceptions of self and others about drinking; a score greater than 9 indicates "problem drinking." The survey also asked partner-bypartner sexual behavior and condom use questions for up to five partners within the prior 6 months. Participants reported the sex of their partners (and sexual identity of male partners), whether regular (e.g. husband/wife, boyfriend/girlfriend) or casual (e.g. "one night stand"), number of times vaginal or anal sex, position in anal sex, and number of protected acts. Unprotected sex (vaginal and anal) was determined by subtracting number of protected sex acts from number of sex acts; all responses greater than zero were coded unprotected. Finally, participants answered questions about their history of STI symptoms and treatment in the last 12 months, HIV testing history, and perceived HIV status.

HIV status was determined through rapid antibody testing on blood samples collected through voluntary counseling and testing (VCT), linked to the participants' behavioral data by study identification number. After completing the survey, we offered all participants VCT, for 
which they provided separate informed consent. Trained counselors provided pre- and post-test counseling. After pre-test counseling, a nurse drew $5 \mathrm{ml}$ of blood from each participant. Participants could elect to receive their results that day, or to return within 3 months of their study visit. Men who received a positive result were referred to clinical care within the PHRU pending the result of CD4 testing of their blood samples. Men with CD4 cell counts less than $200 / \mathrm{mm}^{3}$ were provided with antiretroviral (ARV) treatment free of charge.

\section{Laboratory Procedures}

We followed the South African national standard algorithm for serial rapid testing. All samples were first tested on Determine (Abbott Laboratories, Abbott Park, IL) rapid test kits. Non-reactive samples were interpreted as HIVnegative. Reactive samples were then tested using UniGold (Trinity Biotech, Wicklow, Ireland) rapid test kits. Uni-Gold reactive samples were confirmed as positive. Uni-Gold non-reactive samples were interpreted as indeterminate and sent to the National Health Laboratory Services (NHLS) lab in Johannesburg for confirmatory testing. Additionally, confirmed positive samples were sent to the NHLS lab for CD4 testing.

\section{Data analysis}

We estimated HIV and behavioral risk factor prevalence using RDSAT software version 5.6 (www.respondent drivensampling.org) which adjusted for personal network size and homophily in recruitment. In general, larger personal network sizes and a high degree of homophily would adjust the crude sample proportion downward; by comparison, smaller network sizes and less homophily in recruitment would adjust the crude proportion upward. Demographic and behavioral variables were analyzed in relation to HIV result as the main outcome of interest. RDSAT also provided individual HIV outcome weights for use in multivariable analyses following methods outlined by Heckathorn [18]. Multivariable analyses were conducted (weighted by RDSAT-generated HIV result weights) in SAS version 9.1 (Cary, NC).

Seventy-one participants declined VCT and were thus missing the main outcome of interest. Because RDS analysis takes into account network size and homophily to produce population estimates, declaring the data "missing" would have, in effect, broken the recruitment chains and networks in which these participants were embedded. To preserve our ability to produce estimates using RDS outcome weights, we used multiple imputation to account for missing HIV status. To select variables on which to base the imputation, we first explored bivariate demographic and behavioral predictors of HIV infection in the crude data at $P<0.05$ level. We then constructed a saturated multivariable model using these variables with HIV status as the outcome, and used likelihood ratio testing to develop a restricted model including all variables at $P<0.10$. Next, a logistic regression using the -mim- command in Stata 9.0 (College Station, TX) was run 20 times using a randomly chosen seed to produce 20 separate datasets with imputed values for the 71 missing HIV results. These 20 datasets were then individually exported into RDSAT, which assigned individualized HIV outcome weights to each observation in each dataset. The weights were then merged into their corresponding datasets by participant identification number. Finally, the 20 datasets were stacked in Stata using the -mimstack- command, producing a single dataset with imputed values for all missing HIV results. To ensure that the imputed results were within the boundaries of the two extreme possibilities of all missing results being either negative or positive, we compared HIV prevalence, bivariate associations, and multivariable logistic regression analyses of the imputed results to the two alternative scenarios using the RDSAT generated weights. Each multivariable model included variables associated with HIV infection in any of the three bivariate scenarios at $P<0.10$.

\section{Results}

Recruitment took place over 30 weeks between February and August 2008, and produced a crude sample of 378 MSM. Demographic and sexual identity indicators are presented in Table 1. In adjusted analysis of 363 non-seed respondents, $16.1 \%$ identified as gay, $33.6 \%$ as bisexual, and $43.2 \%$ as straight. All of South Africa's black African ethnic groups were represented in the sample, and all but one participant were black South Africans. Circumcision prevalence was $36.4 \%$, and a majority reported regular partnerships with women $(63.4 \%)$ or men $(69.6 \%)$.

Alcohol was the most commonly used substance (Table 2), with $87.9 \%$ reporting that they drank at least once per month, and $54.5 \%$ reporting 10 or more drinks on a typical day of drinking; $75.9 \%$ of AUDIT scores indicated problem drinking. Other substance use was less common; $25.0 \%$ of the sample had used marijuana, and use of stimulants including ecstasy, cocaine, methcathinone, and methamphetamines was rare, as was injection drug use.

Sexual health indicators for this population were mixed. Few reported STI symptoms in the last year. Although $37.9 \%$ had ever tested, recent HIV testing (i.e. within the last 6 months) was uncommon. Prior to testing in the study, most men perceived that they were HIV-negative $(57.2 \%)$; less than $1 \%$ of MSM perceived that they were HIV-positive. 
Table 1 Crude and population-adjusted demographic indicators of MSM in Soweto Men's Study $(N=363)$

\begin{tabular}{|c|c|c|}
\hline Variable & Crude $^{\mathrm{a}} \%(N)$ & Adjusted \% (95\% CI) \\
\hline \multicolumn{3}{|c|}{ Age (median 23, range 18-48) } \\
\hline $18-24$ & $64.0(235)$ & $69.0(60.6-75.6)$ \\
\hline 25 and older & $36.0(128)$ & $31.0(24.4-39.4)$ \\
\hline \multicolumn{3}{|l|}{ Education } \\
\hline Primary & $1.9(7)$ & $2.3(0.7-4.3)$ \\
\hline Secondary & $79.4(280)$ & $83.6(76.6-87.6)$ \\
\hline Post-secondary & $18.8(64)$ & $14.2(10.3-21.2)$ \\
\hline \multicolumn{3}{|l|}{ Residence } \\
\hline Soweto & $99.5(362)$ & $99.7(99.0-100)$ \\
\hline Other Johannesburg & $0.5(1)$ & $0.3(0.1-0.7)$ \\
\hline \multicolumn{3}{|c|}{ Monthly income in rand ( 7 rand -1 USD) } \\
\hline$<\mathrm{R} 500$ & $77.5(281)$ & $76.6(70.7-84.0)$ \\
\hline R500-999 & $5.8(20)$ & $7.2(2.4-10.3)$ \\
\hline R1000-4999 & $13.8(51)$ & $12.8(8.1-17.9)$ \\
\hline R5000-9999 & $2.1(8)$ & $2.9(0.6-6.3)$ \\
\hline$\geq \mathrm{R} 10000$ & $1.1(3)$ & $0.4(0-1.6)$ \\
\hline \multicolumn{3}{|l|}{ Employment } \\
\hline Unemployed & $64.8(235)$ & $62.3(55.4-69.7)$ \\
\hline Student & $14.6(55)$ & $18.2(12.6-25)$ \\
\hline Laborer & $4.5(16)$ & $3.4(1.7-5.6)$ \\
\hline Shopkeeper & $1.1(4)$ & $1.3(0.1-2.7)$ \\
\hline Clerical & $1.1(3)$ & $0.1(0.0-0.2)$ \\
\hline Professional & $6.1(22)$ & $2.1(0.1-3.8)$ \\
\hline Other & $7.9(28)$ & $12.6(6.8-17.2)$ \\
\hline \multicolumn{3}{|l|}{ Sexual identity } \\
\hline "Gay" & $34.1(120)$ & $16.1(11.3-22.2)$ \\
\hline "Bisexual" & $30.4(112)$ & $33.6(28.1-41.4)$ \\
\hline "Straight" & $31.7(118)$ & $43.2(35.5-50.9)$ \\
\hline \multicolumn{3}{|l|}{ Regular female partner } \\
\hline Yes & $51.2(186)$ & $63.4(55.9-70.8)$ \\
\hline No & 48.8 (177) & $36.6(29.3-44.1)$ \\
\hline \multicolumn{3}{|l|}{ Regular male partner } \\
\hline Yes & $73.0(265)$ & $69.6(64.7-76.7)$ \\
\hline No & $27.0(98)$ & $30.4(23.3-35.3)$ \\
\hline \multicolumn{3}{|l|}{ Circumcision status } \\
\hline Circumcised & $33.6(124)$ & $36.4(30.0-44.8)$ \\
\hline Uncircumcised & $66.1(238)$ & $62.8(52.8-69.4)$ \\
\hline Not sure & $0.3(1)$ & $0.7(0-1.6)$ \\
\hline \multicolumn{3}{|l|}{ Ever been in prison } \\
\hline Yes & $21.7(80)$ & $21.5(16.2-27.0)$ \\
\hline No & $78.3(283)$ & $78.5(73.0-83.8)$ \\
\hline
\end{tabular}

${ }^{a}$ Sub-groups do not always add up to totals due to missing data

The unadjusted results of HIV testing showed that $20.6 \%$ of the sample was HIV-positive, with $18.8 \%$ declining to give a blood sample; of the 307 men who consented to VCT, 115 $(37.5 \%)$ declined to receive their results on the day of their study visit, and none returned within 6 months to collect them.

Our multiple imputation procedure suggested that most of the missing HIV results were negative. Based on this imputation, we present adjusted results of bivariable analyses in Table 3, and multivariable analyses in Table 4. The overall HIV prevalence estimate for this MSM population is $13.2 \%$ (95\% confidence interval (CI) $12.4-13.9 \%$ ), with $33.9 \%$ among gay-identified men, $6.4 \%$ among bisexual-identified men, and $10.1 \%$ among straight-identified MSM. Significant bivariate predictors of HIV infection were age ( 25 or older), gay identity, monthly income greater than ZAR 500, having a regular male partner, purchasing alcohol or drugs for a male partner in exchange for sex, ever having receptive anal intercourse (RAI) with another man, and reporting unprotected insertive (UIAI) or receptive anal intercourse (URAI) with male partners within the last 6 months. HIV infection was significantly less likely among MSM who were circumcised, smoked marijuana within the prior 6 months, had a regular female partner, and reported unprotected vaginal intercourse (UVI) with women. In multivariable analysis, increased odds of infection was associated with age (adjusted odds ratio (AOR) 3.8, 95\% CI 3.2-4.6), gay identity (AOR 2.3, 95\% CI 1.8-3.0), monthly income less than ZAR500 (AOR 1.4, 95\% CI 1.2-1.7), purchasing alcohol or drugs in exchange for sex with another man (AOR 3.9, 95\% CI 3.2-4.7), reporting URAI (AOR 4.4, 95\% CI 3.5-5.7), and reporting between six and nine partners in the prior 6 months (AOR 5.7, 95\% CI 4.0-8.2). Decreased risk of HIV infection was associated with being circumcised, (AOR 0.2, 95\% CI $0.1-0.2$ ), having a regular female partner (AOR $0.2,95 \%$ CI $0.2-0.3$ ), having smoked marijuana in the last 6 months (AOR 0.6, 95\% CI 0.5-0.8), UVI with women (AOR 0.5, 95\% CI 0.4-0.6), and reporting STI symptoms in the last year (AOR 0.7, 95\% CI 0.5-0.8).

\section{Discussion}

The results of the Soweto Men's Study confirm that MSM are at high risk for HIV infection, and demonstrate that HIV is unevenly distributed among MSM subpopulations. At $33.9 \%$, HIV prevalence among self-identified gay men is greater than three times that of bisexual and straightidentified MSM, whose respective estimates of 6.4 and $10.6 \%$ are comparable to the $11.7 \%$ HIV prevalence found among South African men aged 15-49 in the 2005 national survey [19]. In their meta-analysis of HIV prevalence for MSM in developing countries, Baral et al. found MSM in Africa were 3.8 times more likely to be HIV infected than the general population [8], yet our overall prevalence estimate of $13.2 \%$ is comparable to men in the general population. However, as the samples from which Baral 
Table 2 Crude and adjusted HIV behavioral, substance use, sexual health, and HIV prevalence indicators of MSM in Soweto Men's Study $(N=363)$

\begin{tabular}{|c|c|c|}
\hline Variable & Crude $^{\mathrm{a}} \%(N)$ & Adjusted \% (95\% CI) \\
\hline \multicolumn{3}{|l|}{ Sexual behavior } \\
\hline \multicolumn{3}{|l|}{ Sexual history with women } \\
\hline Ever vaginal sex with women & $71.1(261)$ & 86.5(79.7-91.2) \\
\hline \multicolumn{3}{|l|}{ Ever exchange sex with women } \\
\hline Received expensive gifts & $31.8(73)$ & $30.8(23.6-38.0)$ \\
\hline Received money, food, place to sleep & $47.0(101)$ & $44.5(35.2-51.5)$ \\
\hline Received drugs/alcohol & $37.5(86)$ & $39.2(32.2-50.8)$ \\
\hline Provided expensive gifts & $39.0(88)$ & $35.8(28.5-44.9)$ \\
\hline Provided money, food, place to sleep & $54.3(120)$ & $52.6(44.4-60.7)$ \\
\hline Provided drugs/alcohol & $49.1(111)$ & $50.9(45.0-59.8)$ \\
\hline Report female partners in past 6 months & $48.7(179)$ & $60.9(53.2-68.1)$ \\
\hline Any unpro vag with female partner (UVI) & $37.8(140)$ & $45.6(38.1-53.1)$ \\
\hline Any anal with female partner & $11.9(44)$ & $16.3(10.9-21.8)$ \\
\hline Any unpro anal with female partner & $4.8(18)$ & $8.8(4.8-13.3)$ \\
\hline \multicolumn{3}{|l|}{ Sexual history with men } \\
\hline Ever insertive anal sex & $76.7(282)$ & $86.0(80.2-90.8)$ \\
\hline Ever receptive anal sex & $45.6(161)$ & $30.3(23.5-37)$ \\
\hline \multicolumn{3}{|l|}{ Ever exchange sex with men } \\
\hline Received expensive gifts & $36.5(132)$ & $34.7(28.1-40.6)$ \\
\hline Received money, food, place to sleep & $48.4(175)$ & $49.4(40.954 .3)$ \\
\hline Received drugs/alcohol & $49.2(179)$ & $44.9(37.1-51.2)$ \\
\hline Provided expensive gifts & $15.1(54)$ & $9.5(5.8-11.2)$ \\
\hline Provided money, food, place to sleep & $24.3(86)$ & $21.8(15.7-26.7)$ \\
\hline Provided drugs/alcohol & $23.0(81)$ & $17.9(12.9-21.2)$ \\
\hline IAI with male partners (ever) & $77.7(282)$ & $85.2(78.6-90.6)$ \\
\hline Any UIAI with male partners (6 mo) & $28.6(103)$ & $28.0(21.9-33.6)$ \\
\hline RAI with male partners (ever) & $37.8(135)$ & $20.6(15.5-27.0)$ \\
\hline Any URAI with male partner (6 mo) & $17.5(61)$ & $9.5(6.5-14.2)$ \\
\hline Ever been coerced into sex & $21.7(76)$ & $16.0(10.8-21.3)$ \\
\hline \multicolumn{3}{|l|}{ Substance use } \\
\hline \multicolumn{3}{|l|}{ How often do you drink alcohol? } \\
\hline Never & $11.1(41)$ & $12.1(7.5-17.3)$ \\
\hline Once per month & $29.6(108)$ & $28.8(23.0-36.1)$ \\
\hline 2-4 times per month & $32.3(116)$ & $31.5(24.0-36.9)$ \\
\hline $2-3$ times per week & $19.3(69)$ & $17.3(13.0-23.7)$ \\
\hline 4 or more times per week & $7.7(29)$ & $10.3(5.9-14.8)$ \\
\hline Problem drinking (AUDIT > 9) & $75.7(276)$ & $75.9(70.0-82.1)$ \\
\hline \multicolumn{3}{|l|}{ Drug use: used in last 6 months } \\
\hline Marijuana (“dagga”) & $26.5(96)$ & $25.0(20.6-30.8)$ \\
\hline Cocaine & $1.3(5)$ & $0.5(0.1-1.2)$ \\
\hline Ecstasy & $4.0(14)$ & $2.0(0.8-3.7)$ \\
\hline Crystal methamphetamine (“tik") & $0.3(1)$ & $0.5(0.0-1.6)$ \\
\hline Methcathinone ("khat") & $0.3(1)$ & $0.2(-)$ \\
\hline Heroin & $1.1(4)$ & $1.9(0.5-3.6)$ \\
\hline Methaqualone (mandrax) & $1.9(7)$ & $0.9(0.3-1.7)$ \\
\hline Nyaupe & $1.3(5)$ & $2.7(0.5-5.8)$ \\
\hline Gamma hydroxy-butyrate (GHB) & $0.3(1)$ & $0.0(0.0-0.1)$ \\
\hline Ever injected illict drugs & $0.5(2)$ & $2.1(0.0-2.6)$ \\
\hline
\end{tabular}


Table 2 continued

\begin{tabular}{|c|c|c|c|}
\hline & Variable & Crude $^{\mathrm{a}} \%(N)$ & Adjusted \% (95\% CI) \\
\hline & Sexual health and HIV & & \\
\hline & Any STI symptoms (12 months) & $25.9(98)$ & $28.0(26.3-29.7)$ \\
\hline & Ever HIV test & $43.5(158)$ & $37.9(30.6-45.1)$ \\
\hline & Perceived HIV status today & & \\
\hline & Negative & $56.6(188)$ & $57.2(48.0-62.2)$ \\
\hline & Positive & $2.4(8)$ & $0.8(0.2-1.5)$ \\
\hline & Don't know/no answer & $40.4(134)$ & $41.1(35.7-49.4)$ \\
\hline & HIV status & & \\
\hline & Negative & $60.6(224)$ & $69.0(63.0-76.2)$ \\
\hline & Positive & $20.6(69)$ & $10.9(6.5-14.6)$ \\
\hline a Sub-groups do not always add & Declined to test & $18.8(70)$ & $20.1(14.0-26.6)$ \\
\hline
\end{tabular}

et al.'s pooled estimates were drawn were largely derived from convenience samples of men who self-identified as gay or another homosexual identity and were not adjusted for sampling designs, our finding that gay-identified men have a substantially higher odds of HIV infection than nongay identified MSM is largely consistent with the findings of the meta-analysis.

In reporting this finding, we recognize that gay identity is not a behavior, although in township MSM communities gay identity is itself highly correlated with the exclusive practice of RAI, and conversely, self-identifying as bisexual or a straight MSM was highly correlated with the exclusive practice of insertive anal intercourse (IAI) with male partners [5]. Since gay-identified men are also the most visible of MSM in township communities, this finding indicates that it is possible and necessary to begin working immediately with gay-identified men on HIV prevention and treatment, focused not only on individual behaviors, but the disadvantageous structural and socio-cultural contexts that influence their behaviors. Unlike other sub-Saharan African countries, there are no legal barriers to working with gay communities in South Africa.

The Soweto Men's Study is also, to our knowledge, one of the first studies of MSM in Africa to have applied the RDSAT-generated weight outcomes described by Heckathorn [18] to estimate HIV prevalence and to develop multivariable model of HIV risk factors, and the first with an HIV prevalence outcome to account for missing outcome data through multiple imputation. That the imputed model's HIV prevalence estimates were between the two extreme possibilities gives us confidence that the procedure has resulted in a reasonable initial HIV prevalence estimate for this population. Given RDS's popularity with studying MSM populations in sub-Saharan Africa, future behavioral and HIV surveillance studies using RDS may need to follow similar procedures to account for missing HIV data. Other studies have found that MSM who are socially vulnerable may be reluctant to test [12], and that many MSM have prior negative experiences with HIV VCT [20]. It is therefore understandable that MSM may decline to test even in a study setting that guaranteed access to medical care.

Several studies have noted the association between alcohol consumption and sexual risk behaviors [21-23] Our sample was quite homogenous in its drinking behavior, and thus we did not detect a statistically significant association with UAI or HIV infection; we do not conclude that alcohol consumption plays no part in HIV transmission among MSM. On the contrary, purchasing alcohol in exchange for sex with other men predicted HIV infectionand was the only form of transactional sex between men with a significant effect. This speaks to the complex role that substance use and sexual exchange play in the lives of township MSM. Better understanding how all of these factors may contribute to MSM's HIV risk will be important to intervention efforts.

A large number of participants also reported having a regular female partner, and counted at least one woman among their last five partners. Although female partnerships and UVI were associated with lower HIV risk, the comparison group in each case is composed overwhelmingly of gay-identified men who practice RAI with other men, whose risk is much higher. It is important to note that relatively high rates of self-reported UVI (45.6\%) and UIAI with men $(28.0 \%)$ in this population provide ample opportunity for HIV transmission to take place, and suggests that the heterosexual and MSM epidemics are behaviorally linked. MSM who also have sex with women keep their identities and behaviors hidden and are therefore difficult to target with same-sex specific HIV prevention messaging aimed at gay men; in the absence of information this group may be inadvertently increasing the long-term risk of HIV infection to themselves as well as their male and female partners. 
Table 3 Adjusted bivariate associations between selected risk variables and HIV infection (using RDSAT-generated weights)

\begin{tabular}{|c|c|c|}
\hline Variable & $\%(95 \% \mathrm{CI})$ & $P$ \\
\hline \multicolumn{3}{|l|}{ Age } \\
\hline$<25$ years & $10.1(17.3-21.9)$ & \multirow[t]{2}{*}{$<0.0001$} \\
\hline$\geq 25$ years & $19.6(8.8-11.4)$ & \\
\hline \multicolumn{3}{|l|}{ Sexual identity } \\
\hline Gay & $33.9(30.2-37.7)$ & \multirow[t]{3}{*}{$<0.0001$} \\
\hline Bisexual & $6.4(5.3-7.4)$ & \\
\hline Straight & $10.1(8.6-11.6)$ & \\
\hline \multicolumn{3}{|l|}{ Monthly income } \\
\hline$\leq \mathrm{R} 500$ & $11.5(10.4-12.6)$ & \multirow[t]{2}{*}{$<0.0001$} \\
\hline$>\mathrm{R} 500$ & $18.7(15.4-22.1)$ & \\
\hline \multicolumn{3}{|l|}{ Education } \\
\hline Primary & $15.8(9.3-22.3)$ & \multirow[t]{3}{*}{0.48} \\
\hline Secondary & $12.9(11.7-14.3)$ & \\
\hline Post-secondary & $13.7(11.3-16.2)$ & \\
\hline \multicolumn{3}{|c|}{ Number of partners $(6 \mathrm{mo})$} \\
\hline 1 & $12.1(9.7-14.5)$ & \multirow[t]{5}{*}{$<0.0001$} \\
\hline 2 & $12.1(10.2-14.1)$ & \\
\hline $3-5$ & $11.4(10.2-12.6)$ & \\
\hline $6-9$ & $24.2(18.8-29.5)$ & \\
\hline $10+$ & $14.5(9.0-20.0)$ & \\
\hline \multicolumn{3}{|c|}{ Regular female partner } \\
\hline Yes & $5.8(4.9-6.5)$ & \multirow[t]{2}{*}{$<0.0001$} \\
\hline No & $24.4(21.9-26.9)$ & \\
\hline \multicolumn{3}{|c|}{ Regular male partner } \\
\hline Yes & $14.9(13.5-16.2)$ & \multirow[t]{2}{*}{$<0.0001$} \\
\hline No & $9.2(7.2-11.3)$ & \\
\hline \multicolumn{3}{|c|}{ Problem drinking (AUDIT > 9) } \\
\hline Yes & $12.8(11.6-14.1)$ & \multirow[t]{2}{*}{0.14} \\
\hline No & $14.1(11.6-16.7)$ & \\
\hline \multicolumn{3}{|c|}{ Marijuana use (6 mo.) } \\
\hline Yes & $10.5(8.9-12.0)$ & \multirow[t]{2}{*}{$<0.0001$} \\
\hline No & $14.1(12.6-15.5)$ & \\
\hline \multicolumn{3}{|c|}{ Bought drugs or alcohol for male partner } \\
\hline Yes & $25.7(22.5-28.9)$ & \multirow[t]{2}{*}{$<0.0001$} \\
\hline No & $10.4(9.3-11.6)$ & \\
\hline \multicolumn{3}{|c|}{ STI symptoms (12 mo.) } \\
\hline Yes & $14.3(11.9-16.5)$ & \multirow[t]{2}{*}{0.08} \\
\hline No & $12.7(11.4-14.1)$ & \\
\hline \multicolumn{3}{|l|}{ Circumcised } \\
\hline Yes & $5.8(4.8-6.8)$ & \multirow[t]{2}{*}{$<0.0001$} \\
\hline No & $17.3(15.7-18.9)$ & \\
\hline Prison (ever) & & \\
\hline Yes & $13.1(11.3-14.9)$ & 0.93 \\
\hline No & $13.2(11.8-14.5)$ & \\
\hline Receptive anal inte & er) & \\
\hline Yes & $31.3(28.4-34.3)$ & $<0.0001$ \\
\hline No & $5.5(4.7-6.2)$ & \\
\hline
\end{tabular}

Table 3 continued

\begin{tabular}{lrl}
\hline Variable & \multicolumn{1}{l}{$P(95 \% \mathrm{CI})$} & \\
\hline Unprotected insertive anal (last 5 partners) & 0.001 \\
Yes & $15.2(12.9-17.8)$ & \\
No & $12.4(11.0-13.7)$ & \\
Unprotected receptive anal (last 5 partners) & $<0.0001$ \\
Yes & $34.9(29.9-39.8)$ & \\
No & $10.9(9.8-12.0)$ & \\
Unprotected vaginal (last 5 partners) & $<0.0001$ \\
Yes & $5.4(4.6-6.3)$ & \\
No & $18.9(17.1-20.8)$ & \\
\hline
\end{tabular}

Table 4 Multivariable logistic regression for HIV infection (using RDSAT-generated weights)

\begin{tabular}{|c|c|c|}
\hline Variables & $\begin{array}{l}\mathrm{AOR}^{\mathrm{a}} \\
(95 \% \mathrm{CI})\end{array}$ & $P$ value \\
\hline Age $\geq 25$ & $3.8(3.2-4.6)$ & $<0.001$ \\
\hline \multicolumn{3}{|l|}{ Sexual ID } \\
\hline Bisexual & 1 & - \\
\hline Straight & $1.6(1.2-2.0)$ & $<0.001$ \\
\hline Gay & $2.3(1.8-3.0)$ & $<0.001$ \\
\hline Monthly income $<500$ & $1.4(1.2-1.7)$ & $<0.001$ \\
\hline \multicolumn{3}{|l|}{ Number of partners (6 mo) } \\
\hline 1 & 1 & - \\
\hline 2 & $2.8(2.1-3.8)$ & $<0.001$ \\
\hline $3-5$ & $1.9(1.4-2.6)$ & $<0.001$ \\
\hline $6-9$ & $5.7(4.0-8.2)$ & $<0.001$ \\
\hline $10+$ & $2.2(1.5-3.3)$ & $<0.001$ \\
\hline Prison (ever) & $1.1(0.8-1.4)$ & 0.487 \\
\hline Regular female partner & $0.2(0.2-0.3)$ & $<0.001$ \\
\hline Regular male partner & $1.2(1.0-1.5)$ & 0.045 \\
\hline Marijuana use (6 mo) & $0.6(0.5-0.8)$ & $<0.001$ \\
\hline Bought drugs or alcohol for male partner & $3.9(3.2-4.7)$ & $<0.001$ \\
\hline Circumcised & $0.2(0.1-0.2)$ & $<0.001$ \\
\hline Unprotected receptive anal (last 5 partners) & $4.4(3.5-5.7)$ & $<0.001$ \\
\hline Unprotected insertive anal (last 5 partners) & $1.1(0.9-1.3)$ & 0.385 \\
\hline Unprotected vaginal (last 5 partners) & $0.5(0.4-0.6)$ & $<0.001$ \\
\hline STI symptoms (12 mo) & $0.7(0.5-0.8)$ & $<0.001$ \\
\hline
\end{tabular}

a Adjusted for all other variables in the model

Circumcision was associated with lower HIV prevalence. Given that most MSM in our sample reported practicing IAI exclusively, we conclude that there may be a protective association for MSM in South Africa for men who are consistently the insertive partners in anal sex with men. Although a meta-analysis of observational studies of circumcision in MSM populations by Millet et al. could not detect a consistent protective effect, the authors did find a 
non-significant reduction in odds in settings with less than $50 \%$ circumcision prevalence, and concluded that more data on MSM who engage primarily in IAI would be helpful [24]. Given the potential for circumcision to decrease HIV transmission at the population level, and that many MSM who are insertive partners with men also have sex with women, this association should continue to be explored in further observational research with MSM throughout the region.

Our study has several limitations. RDS studies of MSM have been critiqued for overstating claims to unbiased population estimates because the samples actually recruited may not fully represent the underlying population, even after adjustment [25]. Although we attempted systematically to select seeds that would produce a well-networked and diverse sample, it is possible that men who are unemployed and who have lower socioeconomic status (SES) and educational achievement are not well networked with better educated and resourced MSM. Thus unemployed men of lower SES may be overrepresented in our sample. However, our results are likely representative of the most socially vulnerable MSM whose limited income, mobility, and economic opportunity may also limit their access to HIV prevention information, condoms and latex-compatible lubricant, and high-quality health services. It is notable that although black race and Soweto residence were not explicit inclusion criteria, the chains did not leave Soweto except in the case of one Coloured participant, suggesting that the legacy of apartheid continues to limit Soweto MSM's geographic and social mobility. It is also possible that the offer of VCT may have operated both as an additional recruitment incentive $[26,27]$ as well as a disincentive to participating altogether, biasing the results in ways that would be difficult to account for. The interviewer-administered questionnaires may have introduced social desirability bias with respect to self-report of sensitive sexual behaviors, including drug use, receptive $\mathrm{AI}$, and/or unprotected AI. In addition, the multiple imputation procedure we followed for missing HIV results is untested, and to the extent that risk behavior may have been underreported, our imputation method would bias our prevalence estimate towards the extreme possibility of non-testers being HIV-negative. We acknowledge that our adjusted results are likely a conservative estimate of HIV prevalence in the target population.

Finally, our experience with the Soweto Men's Study shows that it is possible to engage MSM in HIV research in the absence of a functioning LGBT organization. It is always preferable to collaborate with and strengthen the capacity of LGBT organizations for MSM HIV research where possible, but the disadvantageous legal and social environment in much of sub-Saharan Africa may inhibit their ability to launch or sustain research and intervention initiatives in their respective communities. Like other
MSM studies in the region, our findings show that it is critical to begin addressing the needs of MSM for HIV prevention and treatment, and that individual MSM, health care practitioners, and researchers can engage in effective collaborations to improve health outcomes in this highly vulnerable population.

Open Access This article is distributed under the terms of the Creative Commons Attribution Noncommercial License which permits any noncommercial use, distribution, and reproduction in any medium, provided the original author(s) and source are credited.

\section{References}

1. Caceres CF, Konda K, Segura ER, Lyerla R. Epidemiology of male same-sex behaviour and associated sexual health indicators in low- and middle-income countries: 2003-2007 estimates. Sex Transm Infect. 2008;84(Suppl 1):i49-56.

2. van Griensven F. Men who have sex with men and their HIV epidemics in Africa. Aids. 2007;21(10):1361-2.

3. Wade AS, Kane CT, Diallo PA, et al. HIV infection and sexually transmitted infections among men who have sex with men in Senegal. Aids. 2005;19(18):2133-40.

4. Kajubi P, Kamya MR, Raymond HF, et al. Gay and bisexual men in Kampala, Uganda. AIDS Behav. 2008;12(3):492-504.

5. Lane T, Shade S, McIntyre J, Morin S. Alcohol and sexual risk behavior among men who have sex with men in South African Township Communities. AIDS Behav. 2008;12(S1):78-85.

6. Baral S, Trapence G, Motimedi F, et al. HIV prevalence, risks for HIV infection, and human rights among men who have sex with men (MSM) in Malawi, Namibia, and Botswana. PLoS ONE. 2009;4(3):e4997.

7. Men who have sex with men (MSM) as presented in VCT data in Kenya. XVI International AIDS Conference. Toronto, Canada; 2006.

8. Baral S, Sifakis F, Cleghorn F, Beyrer C. Elevated risk for HIV infection among men who have sex with men in low- and middleincome countries 2000-2006: a systematic review. PLoS Med. 2007;4(12):e339.

9. Johnson C. Off the map: how HIV/AIDS programming is failing same-sex practicing people in Africa. New York: International Gay and Lesbian Human Rights Commission; 2007.

10. South Africa. Department of Health. HIV \& AIDS and STI National Strategic Plan for South Africa 2007-2011, 2007.

11. Jewkes R, Dunkle K, Nduna M, et al. Factors associated with HIV sero-positivity in young, rural South African men. Int J Epidemiol. 2006;35(6):1455-60.

12. Sandfort TG, Nel J, Rich E, Reddy V, Yi H. HIV testing and selfreported HIV status in South African men who have sex with men: results from a community-based survey. Sex Transm Infect. 2008;84(6):425-9.

13. Ntata PR, Muula AS, Siziya S. Socio-demographic characteristics and sexual health related attitudes and practices of men having sex with men in central and southern Malawi. Tanzan J Health Res. 2008;10(3):124-30.

14. Onyango-Ouma W, Birungi H, Geibel S. Understanding the HIV/ STI risks and prevention needs of men who have sex with men in Nairobi, Kenya. Washington, DC: Population Council; 2005.

15. Heckathorn D. Respondent-driven sampling: a new approach to the study of hidden populations. Soc Probl. 1997;44(2):174-99.

16. Heckathorn D. Respondent-driven sampling II: deriving valid population estimates from chain-referral samples of hidden populations. Soc Probl. 2002;49(1):11-34. 
17. Babor T, Higgins-Biddle J, Saunders J, Monteiro M. AUDIT: the alcohol use disorders identification test. Geneva: World Health Organization; 2001.

18. Heckathorn D. Extensions of respondent driven sampling: analyzing continuous variables and controlling for differential recruitment. Soc Methodol. 2007;37(1):151-207.

19. Shisana O, Rehle T, Simbayi L, et al. South African National HIV prevalence, HIV incidence, behaviour and communication survey, 2005. Cape Town: HSRC Press; 2005.

20. Lane T, Mogale T, Struthers H, McIntyre J, Kegeles SM. "They see you as a different thing": the experiences of men who have sex with men with healthcare workers in South African township communities. Sex Transm Infect. 2008;84(6):430-3.

21. Simbayi LC, Kalichman SC, Jooste S, Mathiti V, Cain D, Cherry C. Alcohol use and sexual risks for HIV infection among men and women receiving sexually transmitted infection clinic services in Cape Town, South Africa. J Stud Alcohol. 2004;65(4):434-42.

22. Simbayi LC, Kalichman SC, Cain D, Cherry C, Jooste S, Mathiti V. Alcohol and risks for HIV/AIDS among sexually transmitted infection clinic patients in Cape Town, South Africa. Subst Abus. 2006;27(4):37-43.

23. Kalichman SC, Simbayi LC, Kaufman M, Cain D, Jooste S. Alcohol use and sexual risks for HIV/AIDS in Sub-Saharan Africa: systematic review of empirical findings. Prev Sci. 2007.

24. Millett GA, Flores SA, Marks G, Reed JB, Herbst JH. Circumcision status and risk of HIV and sexually transmitted infections among men who have sex with men: a meta-analysis. Jama. 2008;300(14):1674-84.

25. Meyer I, Wilson P. Sampling lesbian, gay, and bisexual populations. J Couns Psychol. 2009;56(1):23-31.

26. Johnston L, O'Bra H, Chopra M, et al. The associations of voluntary counseling and testing acceptance and the perceived likelihood of being HIV-infected among men with multiple sex partners in a South African Township. AIDS Behav. 2008. doi: 10.1007/s10461-008-9362-8.

27. Johnston LG, Khanam R, Reza M, et al. The effectiveness of respondent driven sampling for recruiting males who have sex with males in Dhaka, Bangladesh. AIDS Behav. 2008;12(2):294-304. 